\title{
Baseballs or Cricket Balls: On the Meanings of Bullying and Harassment
}

\author{
David Van Fleet ${ }^{1}$, Len White ${ }^{2}$, Ella W. Van Fleet ${ }^{3}$ \\ ${ }^{1}$ Morrison School of Agribusiness, W. P. Carey School of Business, Arizona State University, Mesa, AZ, USA \\ ${ }^{2}$ Active Java, LLC, New York, NY, USA \\ ${ }^{3}$ Professional Business Associates, Scottsdale, AZ, USA \\ Email: dr.vanfleet@gmail.com
}

How to cite this paper: Van Fleet, D. White, L. and Van Fleet, E.W. (2018) Baseballs or Cricket Balls: On the Meanings of Bullying and Harassment. Journal of $\mathrm{Hu}$ man Resource and Sustainability Studies, 6, 131-148.

https://doi.org/10.4236/jhrss.2018.61032

Received: January 12, 2018

Accepted: March 26, 2018

Published: March 29, 2018

Copyright (C) 2018 by authors and Scientific Research Publishing Inc. This work is licensed under the Creative Commons Attribution International License (CC BY 4.0).

http://creativecommons.org/licenses/by/4.0/

\begin{abstract}
This article introduces the use of semantic analysis as a technique for uncovering how the terms bullying and harassment are used. We infer the latent meanings from the titles and abstracts of all articles in the Social Science Citation Index as of September 2016 using Symphony Content Analysis Software. That software applies rigorous techniques to qualitative input to obtain relationships among words and phrases. Content analysis is an empirically based, exploratory methodology. Results suggest that when improper behavior is directed toward children, it is usually identified as bullying. When it involves sexual content, it is sexual harassment. When it is more physical, it may more likely be termed bullying. When it involves name calling or related actions, it is labeled harassment. More importantly, the results show that all these forms of improper behavior are so similar that the distinctions may really involve intentions or impacts rather than the actions, actors, or targets. Suggestions are made about further research applications to better understand terms used in describing dysfunctional behavior.
\end{abstract}

\section{Keywords}

Bullying, Harassment, Workplace, Definitions

\section{Introduction}

Unacceptable behavior has become an increasingly significant problem in our workplaces. The widespread acceptance and use of social media and networking provide previously inconceivable opportunities for unacceptable behaviors with their own unique social, humanitarian, and productivity issues [1] [2] [3] [4]. A multitude of familiar words are typically used as labels for these beha- 
viors-abusive management, aggressive management, dark side behaviors, emotional abuse, incivility, bullying, harassment, misbehavior, misconduct, mobbing, psychological violence, and sexual harassment, to name some of the more common ones (for a more complete set, see [5] and [6]).

Bullying has been frequently reported in schools [7] [8] [9] and in nursing [10] [11], but is also found in virtually all workplaces [12] [13] [14] [15] [16]. Bullying is frequently paired with sexual harassment [17] [18]. Bullying, harassment, and some form of improper, abusive management seem to be the most commonly used words [19] [20] [21]. Further, these are not issues associated with one country. Both bullying and harassment have been reported in numerous countries throughout the world [22]-[28]. The picture is further complicated by company policies and federal laws that, for enforcement reasons, single out and attempt to define the two common types, bullying and harassment.

Bullying and harassment are like baseballs and cricket balls-much alike but also significantly different: both spherical in shape ... about 9 in circumference and $5 \mathrm{oz}$. in weight ... fabricated with a cork center and wrapped in yarn or string ... covered with leather strips sewn together. Although the terms bullying and harassment are widely used, the lack of precise definitions makes it difficult to distinguish between them [29] [30] [31]. There seems to be a need for a greater understanding of the similarities and differences among the many words used to describe or identify improper behavior [32] [33] [34]. This appears particularly the case for bullying and harassment [7] [35] [36] [37] [38] [39].

The purpose of this article is to use qualitative analyses to more clearly understand the similarities and differences between these two words. In an earlier effort to develop a clear understanding of what constitutes bullying, over 450 respondents could completely agree on only one specific behavior as bullying [40]. This means, then, that researchers may not recognize the linkages to others' work if the terms are used inconsistently. Likewise, policy makers and legislators may have difficulty reaching a consensus as varying uses of the terms are employed. Further, if these two terms are significantly different, then distinct policy or legislative statements may be necessary.

\section{Method}

Clearly, a lot of information is available dealing with the many forms of improper workplace behavior, especially bullying and harassment. However, while useful to understanding specific research questions, this results to some extent in information overload [41]. To examine this "information overload" and to assure that the resulting analyses are comprehensive, in September 2016 the Social Science Citation Index was used first to identify all articles dealing with bullying and then a second search for articles dealing with harassment. Then to be even more inclusive [42] a third search for abusive management/supervision was conducted. The bullying search yielded 4667 citations, harassment 5086, and abusive management/supervision 392. After removing common words (e.g. articles and prepositions), numbers, proper names, and abbreviations, the words 
in the titles and abstracts of these citations became the data for the qualitative analysis. They were entered into Symphony Content Analysis Software ${ }^{\odot}$ (http://www.activejava.com/) to be used in forming word clouds.

\subsection{Word Clouds}

In such overload situations, word or tag clouds have emerged as a tool that enables a visual representation of the most prominent words in a body of literature [43] [44] [45] [46]. Word clouds are particularly useful when analyzing word usage in exploratory studies. Word clouds graphically display the frequency of words used by participants of qualitative methods and have become "an innovative approach to quickly summarize and present information from thematic analyses" [47]. Although they do not provide context for the words in the cloud, the visualization reduces the burden of information overload [48] [49] [50]. Word clouds, then, are useful exploratory, analytical tools that are increasingly being used to yield quick visual information about a subject [51] [52] [53] [54] [55].

In Symphony@ word clouds used in this study, the most frequent word is positioned in the center, using the largest font. Then starting above the center, words are added in a clockwise fashion around the center, creating a spiral. The words are added in the descending order of frequency. As the word frequency goes down, the font size is reduced and the color is changed to accentuate the change in font size. The clouds are more qualitative than quantitative. They do not tell how many more times a word appears than another; they only indicate that a word appears more often. If the font sizes of two words are different from each other, it indicates that, given the range of word frequencies in that set of data, one word appears more often than another.

It was anticipated that clouds focused on the concepts of Bullying, Harassment, and Abusive Management would be different but with some overlap. Figure 1 is a hypothetical Venn diagram suggesting what those areas of overlap might look like (the sizes and amount of overlap are illustrative only).

Area 1: Words unique to Bullying,

Area 2: Words unique to Harassment,

Area 3: Words unique to Abusive Management,

Area 4: Words common to both Bullying and Abusive Management,

Area 5: Words common to both Harassment and Abusive Management,

Area 6: Words common to both Bullying and Harassment,

Area 7: Words common to all three concepts.

\section{Cloud Results}

In forming the word clouds, only the 50 most frequent words were used so as to make visualization of the concept clearer (visual clarity increases as the number of displayed words decrease). Figures 2-4, then, are the word clouds for Bullying, Harassment, and Abusive Management. Figure 2 shows the words closest to Bully as behave, experience, social, victim, relate, violence, associate, age, self, and effect. Figure 3 shows the words closest to Harass as behave, experience, 


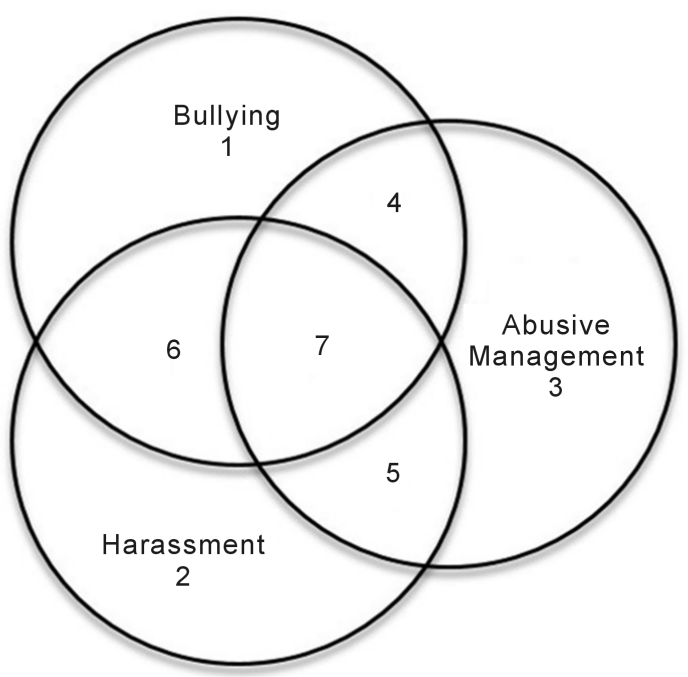

Figure 1. Hypothetical venn diagram of relationships of most frequent words.

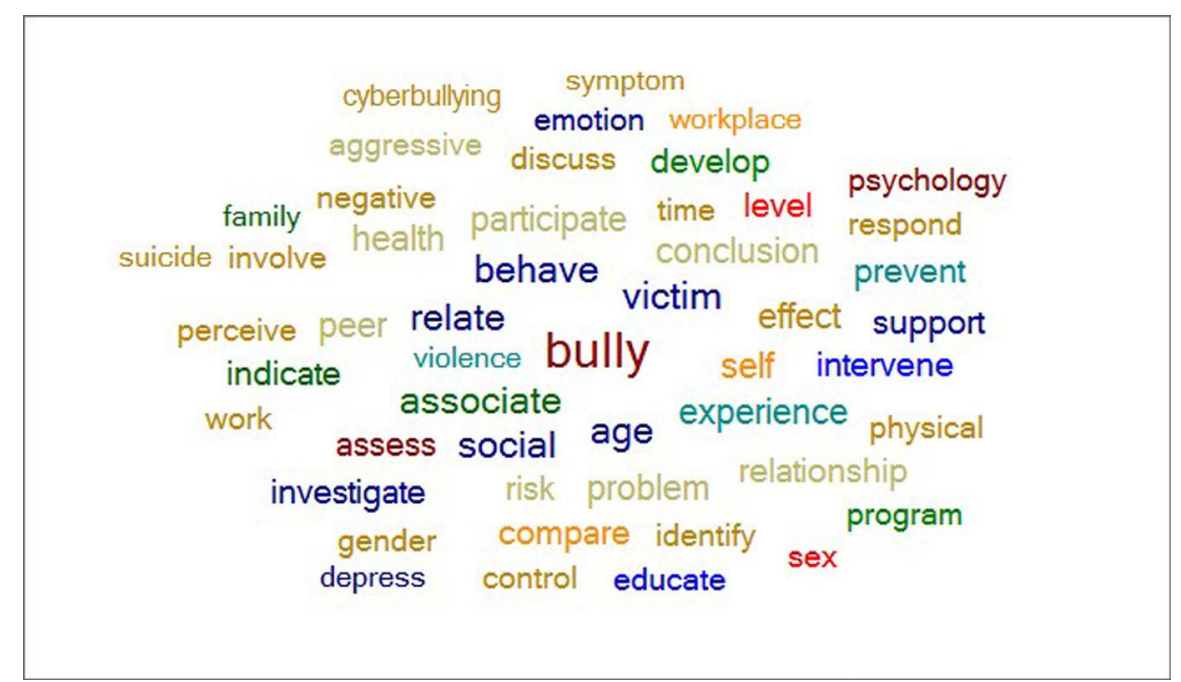

Figure 2. Cloud diagram of bullying.

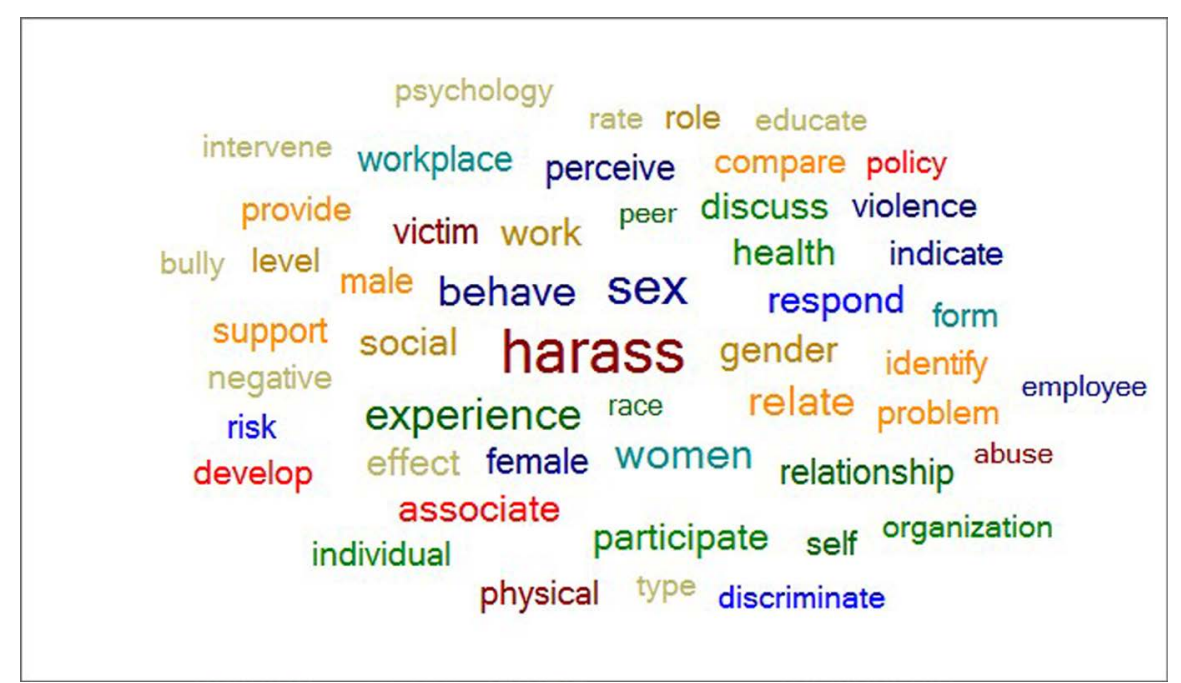

Figure 3. Cloud diagram of harassment. 


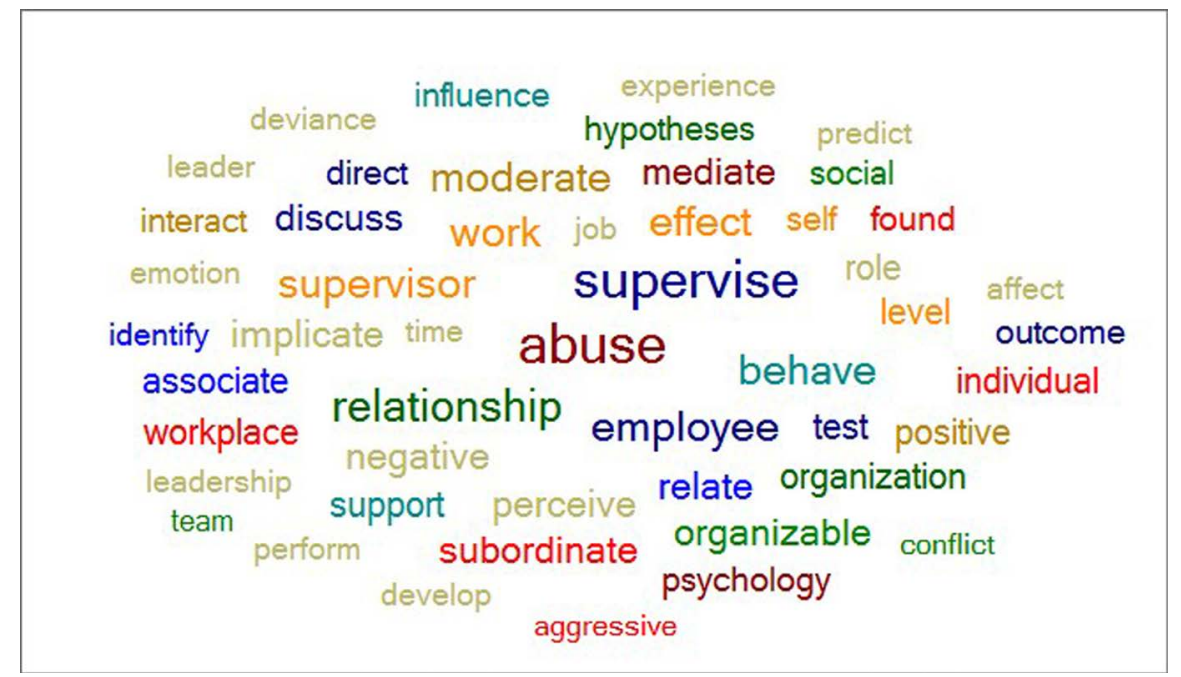

Figure 4. Cloud diagram of abusive management.

social, sex, respond, gender, relate, and race; but male, female, and women are also nearby. Figure 4 shows the words closest to Abusive Management as behave, supervise, supervisor, time, relationship, and employee; but work, job, role, level, and effect are also nearby. In these clouds showing only the 50 most frequent words, the cloud for Bully does not contain harass or abuse and the cloud for Abuse does not contain bully or harass but the cloud for Harass does contain both Bully and Abuse. This suggests that when scholars are writing about bullying, they only infrequently mention harassment or abuse and likewise when their focus is on abusive management, bullying and harassment are mentioned only infrequently. Yet when the focus is on harassment, both bullying and abuse are mentioned perhaps indicating that harassment is the more inclusive concept. However, these clouds do have other words in common which suggests that, while different, there are areas where these three concepts are clearly related; they overlap in some way.

To better understand the relationships among these sets of words, the entire set of words in each area in Figure 1 was examined using Symphony®. The results were quite different from the hypothetical arrangement shown in Figure 1. After removing non-applicable words (articles, prepositions, proper names, specific geographic locations, and terms associated purely with research methods (logit, intercorrelations, etc.), our dataset consisted of 14,129 unique words. The three areas associated with Abusive Management were the smallest, with $0.71 \%$ in Area 3 (Abusive Management only), and $0.44 \%$ and $0.32 \%$ respectively in the overlap Areas 4 and 5. So, Abusive Management was almost totally subsumed by Bullying and Harassment. On the other hand, the combination of words that Bullying and Harassment (Areas 6 and 7) have in common is $43.35 \%$. Bullying only (Area 1 ) has $23.71 \%$ and Harassment only (Area 2 ) has $32.32 \%$. So, with over $99 \%$ of the words associated with Bullying and/or Harassment, further examination of Abusive Management is discontinued. While Bullying and Harassment are different, they may be more alike than they are different. A Venn 
diagram then would look more like that in Figure 5 (again, the sizes and amount of overlap are not exact; they are illustrative only). Clearly, there is more in common than different in these sets of words.

When the words that occur four or more times in the Bullying and Harassment sets are examined, the situation changes markedly. Again, referring to the areas in Figure 5, words that appear in the Bullying set with no overlapping (Area 1) total only 264. Those in the Harassment only set (Area 2) total 446. And those in the overlap between Bullying and Harassment (Area 3) total 4664. Table 1 shows the 30 most frequent words associated with each of those sets. This suggests that Bullying and Harassment are far more alike than they are different.

In Table 1 almost half of the 30 most frequent words that appear only in the Bullying set (Figure 5, Area 1) suggest medical/health conditions that exist in the target (amygdala, auditory, bulimia, deaf, dyslexia, dyslexic, eczema, eyeglass, gelotophobes, gelotophobia, IUD, monozygotic, stutter, syndemic). Similarly, other words might also be associated with either the target or the actor (aboriginal, cool, defiant, noninvolved, orphan, stature, twins, unemotional). Using target to refer to victims and actor to refer to harassers or perpetrators [56] reduces the emotional content of the words and is used here. It would seem, then, that when the focus is on the target, the dark side behavior is most likely to be identified as bullying. So, when children instead of adults are the targets, bullying is the word most often used, and that also might account for other frequent words dealing with the where or when the incident occurred (breakfast, kid screen, lunchtime, preschool, preservice). Or maybe it is because bullying a child is viewed as more outrageous or because child bullies and child targets are not as adept at hiding their actions/reactions.

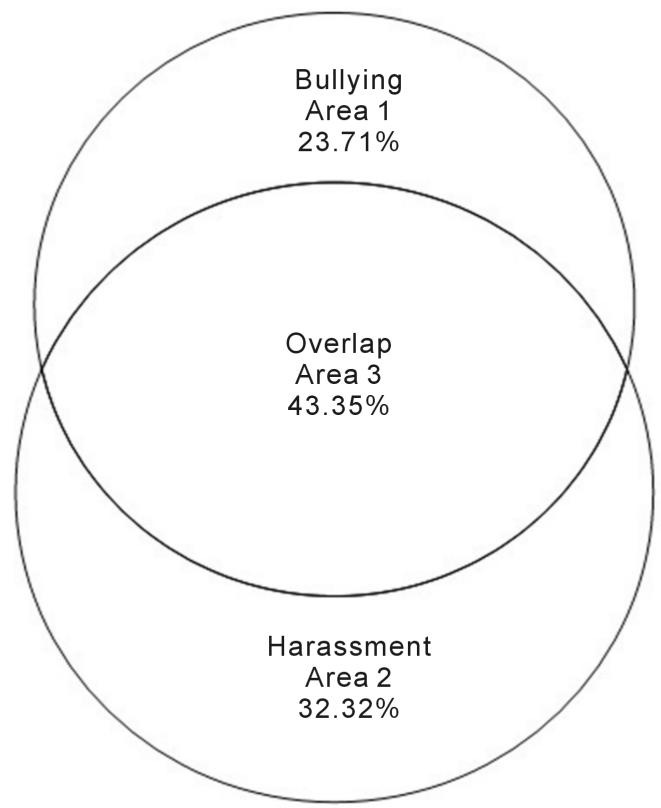

Figure 5. Venn diagram after removing abusive management. 
Table 1. Words occurring most frequently.

\begin{tabular}{|c|c|c|c|c|c|}
\hline \multicolumn{6}{|c|}{ Most Frequently Occurring Words That Mention: } \\
\hline \multicolumn{2}{|c|}{ Bullying Only (Figure 5, Area 1) } & \multicolumn{2}{|c|}{ Harassment Only (Figure 5, Area 2) } & \multicolumn{2}{|c|}{ Overlap (Figure 5, Area 3) } \\
\hline Word & Count & Word & Count & Word & Count \\
\hline Stutter & 105 & Abort & 150 & Bully & 21,753 \\
\hline Preschool & 85 & Plaintiff & 112 & Victim & 11,418 \\
\hline Kid screen & 49 & Juror & 70 & Sex & 9699 \\
\hline Twins & 42 & Dowry & 53 & Harass & 8727 \\
\hline Orphan & 40 & Syringe & 46 & Behave & 7817 \\
\hline Breakfast & 25 & Apology & 32 & Social & 5487 \\
\hline Unemotional & 23 & Bribery & 31 & Experience & 5362 \\
\hline Inhale & 20 & Post deployment & 31 & Associate & 5281 \\
\hline Eczema & 19 & Diastole & 29 & Relate & 4891 \\
\hline Gelotophobia & 19 & Eeoc & 29 & Health & 4565 \\
\hline Aboriginal & 18 & Dod & 26 & Work & 4152 \\
\hline Syndemic & 17 & Quid pro quo & 26 & Peer & 3981 \\
\hline Drunken & 16 & Woman's & 26 & Effect & 3947 \\
\hline Defiant & 14 & Token & 24 & Gender & 3834 \\
\hline Noninvolved & 14 & Hill & 23 & Women & 3722 \\
\hline Stature & 14 & Despliegue & 21 & Relationship & 3709 \\
\hline Auditory & 13 & Sanitize & 21 & Self & 3672 \\
\hline Bulimia & 13 & Cadet & 20 & Workplace & 3529 \\
\hline Chef & 13 & Dancer & 20 & Perceive & 3500 \\
\hline Deaf & 13 & Needle & 20 & Problem & 3444 \\
\hline Lunchtime & 13 & Opioid & 20 & Violence & 3365 \\
\hline Cool & 12 & Clergy & 19 & Risk & 3322 \\
\hline Dyslexia & 12 & Ada & 18 & Participate & 3158 \\
\hline Monozygotic & 12 & Cyclist & 18 & Respond & 3157 \\
\hline Amygdala & 11 & Repeal & 17 & Age & 3135 \\
\hline Dyslexic & 11 & Antigay & 15 & Level & 2997 \\
\hline Eyeglass & 11 & City's & 15 & Aggressive & 2946 \\
\hline Gelotophobes & 11 & Copulate & 15 & Support & 2838 \\
\hline Iud & 11 & Landlord & 15 & Intervene & 2648 \\
\hline Preservice & 11 & Episteme & 15 & Physical & 2526 \\
\hline
\end{tabular}


The pattern for words only in the Harassment set (Figure 5, Area 2) is not as clear. The target is mentioned twice (cyclist, dancer), the actor is also mentioned twice (clergy, landlord), and cadet and antigay could possibly be either. The action or request was mentioned four times (bribery, copulate, dowry, quid pro quo). However, six medical terms were noted (abort, diastole, needle, opioid, sanitize, syringe) and seven legal or regulatory terms appear (ADA, DOD, EEOC, episteme [knowledge], juror, plaintiff, repeal). This coupled with there being almost twice as many words for Harassment compared to Bullying suggests both the more complex nature of the term and the fact that one special subset of harassment, sexual harassment, receives a great deal of scrutiny among researchers.

It is no surprise, then, that a mixture of results is observed when examining the words appearing only in overlapping Bullying and Harassment sets (Figure 5, Area 3). There are words associated with targets or actors (age, disable, disorder, gay, gender, health, level, masculine, obese, peer, pupil, relationship, self, sex, staff, women), words associated with where or when (grade, social, work, workplace), and words with legal associations (court, crime, inform, legal, offend). But there also are numerous words associated with action or the result of action (aggressive, assault, behave, bully, harass, participate, respond, stalk, suicide, tease, trauma, victim, violence, violent). This suggests that an examination should focus solely on such action-oriented words, which we did next (see also, [40]).

In examining only action-oriented words, the Bullying Only set (Figure 5, Area) has some words that are positive and convey what would not be thought of as bullying. As shown in Table 2, overwhelmingly the most frequent words in this set involve physical actions, although some also are verbal. As shown in Table 3, Harassment Only (Figure 5, Area 2) like the Bullying only set has numerous words that involve physical actions and some that are verbal. However, in terms of frequency, the Harassment Only set contains sexual references and, more interestingly, it contains numerous words involving "labeling," name calling, or threatening to label the target. The attention paid to sexual harassment accounts for the presence of those sexual terms [57]. Focusing on action words, then, suggests that bullying is more likely to involve physical, nonsexual behaviors while harassment is more likely to involve labeling behavior or specific sexual behavior.

Noting the sizable overlap between Bullying and Harassment, a word cloud of the entire set of words was obtained. This visualization based on the frequency of words in the database clearly shows bully(ing) as the central word with harass close by. Behave, experience, victim, self, associate, and relate are also nearby as are social, sex, peer, and work. Abuse and aggressive appear but are more distant. The frequency of occurrence is not the complete story, though. Both words occur frequently in this database, but a more interesting question is how often are they used together? Understanding that involves one final step in the analysis. 
Table 2. Bullying action oriented words.

\begin{tabular}{|c|c|c|c|c|c|}
\hline \multicolumn{6}{|c|}{ BULLYING ONLY (Top counts) } \\
\hline Positive & Count & Physical & Count & Verbal & Count \\
\hline Console & 4 & Cheat & 7 & Affront & 3 \\
\hline Makeup & 3 & Defiant & 14 & Curse & 4 \\
\hline Reassess & 3 & Detain & 3 & Deride & 3 \\
\hline \multirow[t]{9}{*}{ Reorient } & 3 & Glee, grin & 3 & Quarrel & 3 \\
\hline & & Haunt & 3 & Spiel & 4 \\
\hline & & Massacre & 6 & & \\
\hline & & Rampage & 6 & & \\
\hline & & Remand & 3 & & \\
\hline & & Shun & 9 & & \\
\hline & & Snatch & 5 & & \\
\hline & & Spank & 5 & & \\
\hline & & Trail & 6 & & \\
\hline
\end{tabular}

Table 3. Harassment action oriented words.

\begin{tabular}{cccccccc}
\hline \multicolumn{7}{c}{ HARASSMENT ONLY (Top counts) } \\
\hline Sex & Count & Labelling & Count & Physical & Count & Verbal & Count \\
\hline Abort & 150 & Advertise & 8 & Bash & 4 & Groan & 3 \\
Copulate & 15 & Announce & 7 & Batter & 13 & Grunt & 3 \\
Dates & 6 & Blackmail & 5 & Clubbing & 2 & Menace & 8 \\
Desexualize & 10 & Disgrace & 3 & Fracture & 4 & Scold & 3 \\
Flirt & 6 & Insinuate & 4 & Glance & 3 & Scorn & 3 \\
Kiss & 4 & Promulgate & 5 & Siege & 2 & & \\
Procreate & 4 & Relabeled & 3 & Confiscate & 7 & & \\
Seduction & 13 & Quid pro quo & 26 & Startle & 4 & & \\
& & Slander & 3 & Rob(bery) & 2 & & \\
& & Smear & 5 & Wield & 2 & & \\
& & Ultimatum & 9 & Shot & 3 & & \\
& & & & & \\
\end{tabular}

\subsection{Multidimensional Scaling}

In addition to developing word clouds, Symphony Content Analysis Software@ can perform multidimensional scaling (MDS). MDS has been shown to be useful in exploratory data analysis [58] [59] [60]. For large data sets, MDS is used to represent high dimensional data in low dimension space to reduce the effect of "noise" and improve information retrieval [61]. It provides a way to better 


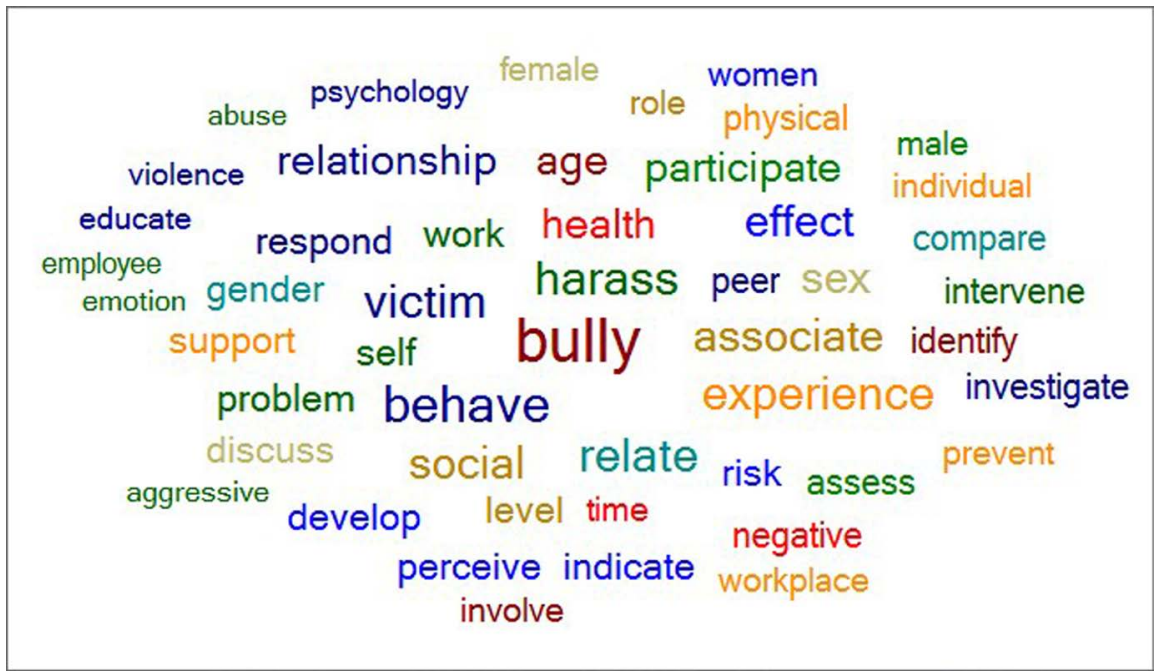

Figure 6. Cloud diagram of entire set.

understand through visualization the similarity or dissimilarity of individual words in a database [62] [63] [64]. As it had been used to study deviant workplace behaviors [65], its use here seemed particularly warranted.

\section{MDS Results}

MDS analysis identifies each word in a distance matrix of $N$-dimensional space with similar words near each other and dissimilar ones farther from each other. In our analysis, the distance between two words was determined by the percent of occurrences of one word appearing in an abstract with no match for another word. For example, if Words A and B appear in an abstract once, the distance is zero; if Word A appears but not Word B, the distance is one; or if Word A appears twice and Word B once, the distance is one. These values are added and divided by the sum of the occurrences of the two words with the resulting percent indicating the distance between the two words. The MDS analysis also took an additional step in determining the distances. In addition to how often two words appear together, it also factors in how often all other words appear with either of those words. In other words, the distance is a composite of the differences in the distances word A and word B have from all the other words as well.

The MDS analysis translates the distances into coordinates on a graph. This is done by finding coordinates that minimize how far the points assigned to the words are from their calculated distances. The more dimensions used, the closer they are to being identical and the closer the system is to a zero goodness-of-fit value known as stress. Three dimensions were used, as that is the limit of human comprehension. All the words start at a given coordinate, then one-by-one they are placed in a variety of trial coordinates to find the one that produces the lowest stress for the overall system. This is repeated for all the words over and over until a configuration of coordinates has been discovered such that if a word is moved, the overall stress will not decline.

The resulting 3-dimensional plot is shown in Figure 7 (words overlap when 


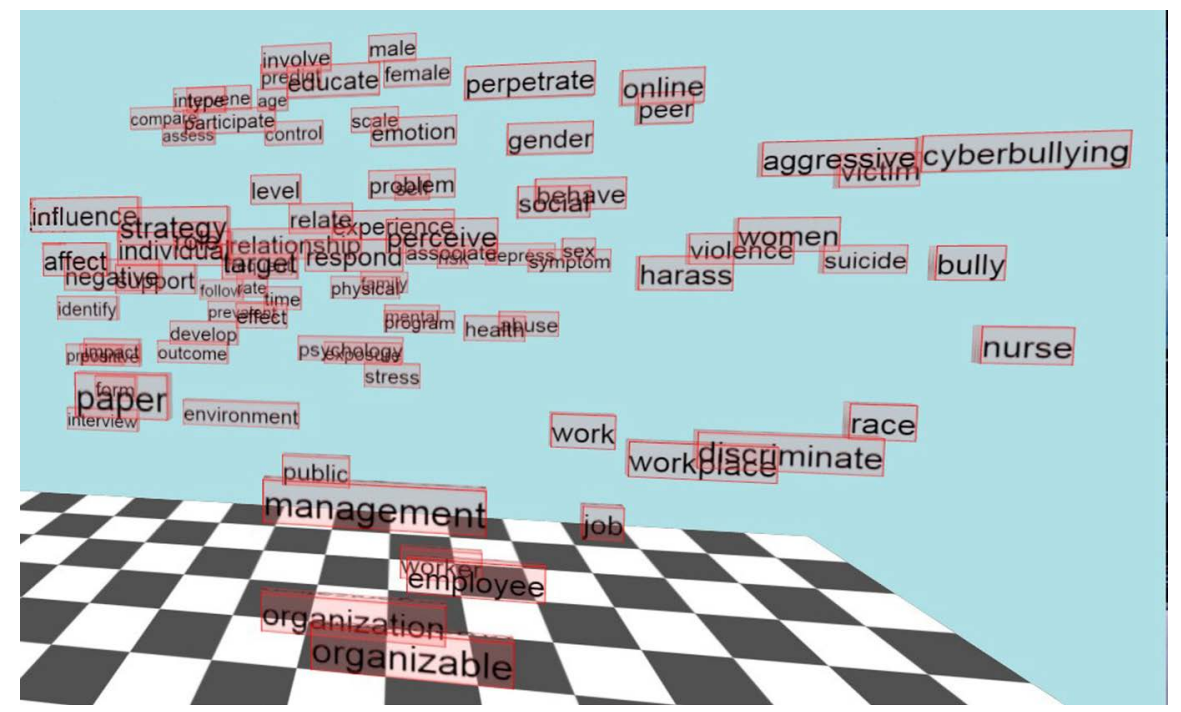

Figure 7. MDS diagram of entire set.

portraying three dimensions in two-dimensional space). Examining the MDS plot for words in close proximity indicates that bully, harass, violence, women, and suicide are clustered, with aggressive, victim, and cyberbullying clustering nearby. Work, workplace, discriminate and race are also clustered with another nearby cluster of public, management, job, worker, employee, organization, and organizable. Nurse stands alone near bully. Bully(ing) and harass(ment) appear relatively close to one another, suggesting that they frequently occur together and share many words in common. They are separated only by the words women, violence, and suicide which suggests that those are key terms in differentiating bullying and harassment. Nearby are aggressive, victim, cyberbullying, race, discriminate, and work and workplace, suggesting that those terms are related to both concepts.

\section{Discussion}

Some of these results suggest that bullying and harassment are different, yet other results point to their sameness. Satan and the Devil may be the same but people interpret and discuss them in different ways. Similarly, bullying and harassment may be interpreted and discussed in different ways. Multidimensional Scaling would show them far apart if not for the inclusion of the similarities that they have with other frequently used words. When improper behavior is directed toward children, it is usually identified as bullying. When improper behavior involves sexual content, it is sexual harassment. When improper behavior is more physical, it may more likely be termed bullying. When improper behavior involves name calling or related actions, it is labeled harassment. When improper managerial behavior involves verbal criticism and is done publicly, it is bullying [40].

All these forms of improper behavior, while different, are similar. Does that matter? If so, why? First, the label that is applied by one researcher, employee, 
company policy, etc. may not apply at all to the behavior that was given the same label by another person. Like baseball or cricket ball, the label may connote a different act from what was intended. Indeed, the distinctions may really require identifying intentions of the actor and impacts on the target rather than the actions, the actors, or the target. For example, what motivated the actor or what was the actor consciously or unconsciously trying to achieve? How does it affect the individuals involved, others, or the organization? It is important to note, for instance, that both bullying and harassment involve actions that suggest the exercising of control over another individual. So, the important question becomes not so much their common or different techniques but rather why the actor feels a need to exercise control.

Are repeated incidents a necessary aspect of either bullying or harassment? MacKinnon [66] says, "The sexual harassment may occur as a single encounter or as a series of incidents at work." While no words suggesting repetition emerged as high-frequency words, some were found when the dataset was examined for words that connote repetition. "Repeat" occurred in the Bullying set 211 times and 104 times in the Harassment set, and "persist" 122 times in each set. Like many of the action words, these are infrequent but notable. So negative behavior that is repeated may be labeled differently by different persons or organizations. Again, the labels are viewed as alike but also different.

\section{Limitations and Future Research}

As with all studies, this one has limitations. First, our inclusive sampling method included articles in languages other than English and articles dealing almost exclusively with schools and/or children. The latter may reflect more than just improper behavior in the workplace. Second, words can have different meanings so the interpretations and classifications which were used here may not correspond to those used by others. Thus, future research is needed.

Because both bullying and harassment involve the actor exercising control over the target, future research should focus on the "why." Why do some individuals feel the need to control others in this way? What is the intent of the bullying? What impact or result does the actor want? Assuming that sexual favors are the intent of sexual harassment, what is the intent of other forms of harassment? Understanding the intent or purpose of bullying and harassment should enable better approaches for dealing with such behaviors.

Future research also should identify the factors which lead teasing or joking to morph into bullying or harassment and when this can be sublimating or cathartic. The most salient aspects of elements of the workplace, actors, targets, and external influences that lead to improper behavior should be specified [67]. Then research should explore combinations of these that are more likely than others to influence perceptions and reality of what is improper behavior. More specifically, research is needed 1) to identify the characteristics that are common to actors or organizations [68] that will help organizations screen out or terminate 
such actors; 2) to develop an operational description that distinguishes aggressive behavior that is improper or inappropriate from aggressive behavior that is proper or appropriate; and 3) to provide a better understanding of who the targets are so that organizations can avoid or remediate problems and develop more and better training programs [69].

Questions that might be addressed in future research also could include:

1) What leads to understanding, acceptance, and change so that effective training and education can occur?

2) How can individuals or organizations intervene in specific situations to curtail negative outcomes?

3) When is such intervention necessary? The line would seem to be drawn by the actor's impact on the target and all the ambient effects.

\section{Conclusions}

The fundamental conclusion of this study is that a clearer understanding of the similarities and differences between the concepts of bullying and harassment can be gained through qualitative analysis. In particular, the use of word clouds and Multidimensional Scaling to examine the large set of words used by researchers has identified many of those similarities and differences.

This analysis indicates that just like baseballs and cricket balls, bullying and harassment are similar but not identical. Where does one draw the line to separate them? Like the Sorites Paradox of trying to decide the precise moment when a tadpole becomes a frog [70] — which cannot be done-we may not know when or if bullying morphs into harassment, or vice versa. The analysis presented here suggests that the inclusion of articles dealing with Abusive Management did not contribute much as the Abusive Management words were largely subsumed by the Bullying and Harassment sets of words. However, the analysis did highlight clear differences between bullying and harassment as used by researchers. When writing about bullying, researchers only infrequently mention harassment or abuse and likewise, when focused on abusive management, bullying and harassment are only infrequently mentioned. When the research is focused on harassment, both bullying and abuse are mentioned. Harassment involved more words than Bullying. The fact that articles about harassment frequently include bullying and abuse may suggest that either it is a more complex phenomenon or that it is being researched and discussed more, or both. This may be due in part to the subset of harassment, sexual harassment, receiving a great deal of scrutiny among researchers.

Nevertheless, our word cloud formations and analyses do help us visualize more clearly the concepts of bullying and harassment as mentioned by researchers.

Bullying. Bullying includes name calling, pushing and shoving physically or verbally, and threatening. Bullying is perceived as being done by someone more powerful emotionally, physically, or organizationally. It appears that when the 
focus is on a specific target, the improper behavior is likely identified as bullying, especially when children are the targets. While most often associated with children, bullying also occurs among adults acting in childish behavior. In addition, bullying behavior seems to be displayed more willingly than harassment in an open or public setting.

Harassment. Harassment includes "labeling," name calling, or threatening to label the target. Harassment also is associated with organizations and workplaces. Harassment may also be associated with violent actions including suicide. Non-sexual harassment is likely to be perceived as behavior that is repeated over some period of unstated time including stalking. The term is used in legal matters; and when sexual references are involved, it is differentiated by the label sexual harassment.

Using this or similar qualitative analyses to further reflect the meaning of these terms, current perceptions and imprecise definitions can be refined to obtain more acceptable, inclusive definitions. On the other hand, because these two concepts have so much in common, separate policy or legislative statements need not be developed. Modeling the EEOC definition of sexual harassment in the workplace (https://www.eeoc.gov/eeoc/publications/fs-sex.cfm), a more inclusive definition might be:

Unwelcome verbal or physical conduct constitutes bullying or harassment when this conduct explicitly or implicitly affects an individual's employment, unreasonably interferes with an individual's work performance, or creates an intimidating, hostile, or offensive work environment.

Using this more inclusive definition in policy statements, organizations can train personnel to recognize and deal with improper behavior, whatever the label.

\section{References}

[1] Mainiero, L. and Jones, K. (2013) Sexual Harassment versus Workplace Romance: Social Media Spillover and Textual Harassment in the Workplace. Academy of Management Perspectives, 27, 187-203. https://doi.org/10.5465/amp.2012.0031

[2] Lucero, M.A., Allen, R.E. and Elzweig, B. (2013) Managing Employee Social Networking: Evolving Views from the National Labor Relations Board. Employee Responsibilities and Rights Journal, 25, 143-158.

[3] Sewell, G. and Barker, J.R. (2006) Coercion versus Care: Using Irony to Make Sense of Organizational Surveillance. Academy of Management Review, 31, 934-961. https://doi.org/10.5465/AMR.2006.22527466

[4] Tabak, F. and Smith, W.P. (2005) Privacy and Electronic Monitoring in the Workplace: A Model of Managerial Cognition and Relational Trust Development. Employee Responsibilities and Rights Journal, 17, 173-189. https://doi.org/10.1007/s10672-005-6940-Z

[5] Vardi, Y. and Weitz, E. (2016) Misbehavior in Organizations: A Dynamic Approach. 2nd Edition, Routledge, NY.

[6] Einarsen, S., Hoel, H. and Cooper, C. (2002) Bullying and Emotional Abuse in the Workplace: International Perspectives in Research and Practice. Taylor \& Francis, 
Boca Raton, FL.

[7] Straus, S. (2011) Bullying vs. Sexual Harassment-Do You Know the Difference? Ms. Magazine Blog, November 15, 2011.

msmaga-

zine.com/blog/2011/11/15/bullying-vs-sexual-harassmentdo-you-know-the-differen $\mathrm{ce} /$

[8] Smokowski, P.R. and Kopasz, K.H. (2005) Bullying in School: An Overview of Types, Effects, Family Characteristics, and Intervention Strategies. Children \& Schools, 27, 101-110. https://doi.org/10.1093/cs/27.2.101

[9] Espelage, D.L. and Swearer, S.M. (2003) Research on School Bullying and Victimization: What Have We Learned and Where Do We Go from Here? School Psychology Review, 32, 365-383.

[10] Berry, P.A., Gillespie, G.O.L., Fisher, B.S., Gormley, D. and Haynes, J.T. (2016) Psychological Distress and Workplace Bullying among Registered Nurses. The Online Journal of Issues in Nursing, 21.

https://www.ncbi.nlm.nih.gov/pubmed/27857181

[11] Houck, N.M. and Colbert, A.M. (2017) Patient Safety and Workplace Bullying: An Integrative Review. Journal of Nursing Care Quality, 32, 164-171.

[12] Crothers, L.M. and Lipinski, J. (2014) Bullying in the Workplace: Causes, Symptoms, and Remedies. Routledge/Taylor \& Francis, NY.

[13] Einarsen, S., Hoel, H., Zapf, D. and Cooper, C.L. (Eds.) (2011) Bullying and Harassment in the Workplace: Development in Theory and Practice. 2nd Editon, Taylor and Francis, Boca Raton, FL.

[14] Parzefall, M. and Salin, D. (2010) Perceptions of and Reactions to Workplace Bullying: A Social Exchange Perspective. Human Relations, 63, 761-780. https://doi.org/10.1177/0018726709345043

[15] Rayner, C. and Cooper, C.L. (2006) Workplace Bullying. In: Kelloway, E., Barling, J. and Hurrell Jr., J., Eds., Handbook of Workplace Violence, Sage, Thousand Oaks, CA, 47-90. https://doi.org/10.4135/9781412976947.n7

[16] Rayner, C. and Keashley, L. (2005) Bullying at Work: A Perspective from Britain and North America. In: Fox, S. and Spector, P.E., Eds., Counterproductive Work Behavior. Investigations of Actors and Targets, American Psychological Association, Washington DC, 271-296. https://doi.org/10.1037/10893-011

[17] Stein, N.D. and Mennemier, K.A. (2011) Addressing the Gendered Dimensions of Harassment and Bullying: What Domestic and Sexual Violence Advocates Need to Know. Critical Issue Brief, The National Resource Center on Domestic Violence \& the National Sexual Violence Resource, Harrisburg, PA.

[18] Stein, N. (2010) Commentary: Sexual Harassment Left Behind: What the "Bullying" Framework Is Doing to Civil Right Laws and Framework. Research \& Action Report, 32, 6-7.

[19] Jenkins, M. (2013) Preventing and Managing Workplace Bullying and Harassment: A Risk Management Approach. Australian Academic Press, Toowong, QLD.

[20] Ramsay, S., Troth, A. and Branch, S. (2010) Work-Place Bullying: A Group Processes Framework. Journal of Occupational and Organizational Psychology, 84, 799-816. https://doi.org/10.1348/2044-8325.002000

[21] Notelaers, G., Vermunt, J.K., Baillien, E., Einarsen, S. and De Witte, H. (2011) Exploring Risk Groups Workplace Bullying with Categorical Data. Industrial Health, 49, 73-88. https://doi.org/10.2486/indhealth.MS1155 
[22] Saguy, A.C. (2011) French and U.S. Legal Approaches to Sexual Harassment. Travail, Genre et Sociétés, 49, 236-257.

[23] Rosenthal, P. and Budjanovcanin, A. (2011) Sexual Harassment Judgments by British Employment Tribunals 1995-2005: Implications for Claimants and Their Advocates. British Journal of Industrial Relations, 49, S236-S257. https://doi.org/10.1111/j.1467-8543.2010.00820.x

[24] Hoel, H. and Einarsen, S. (2010) The Effectiveness of Anti-Bullying Regulations: The Case of Sweden. European Journal of Work and Organizational Psychology, 19, 30-50. https://doi.org/10.1080/13594320802643665

[25] Loh, J., Restubog, S.L.D. and Zagenczyk, T.J. (2010) Consequences of Workplace Bullying on Employee Identification and Satisfaction among Australian and Singaporeans. Journal of Cross-Cultural Psychology, 41, 236-252.

[26] Gorman, E. (2008) The Politics of Sexual Harassment: A Comparative Study of the United States, the European Union, and Germany. Gender \& Society, 22, 828-830. https://doi.org/10.1177/0891243208320252

[27] Harthill, S. (2008) Bullying in the Workplace: Lessons from the United Kingdom. Minnesota Journal of International Law, 17, 247-302.

[28] Smith, P.K., Cowie, H., Olafsson, R.F. and Liefooghe, A.P.D. (2002) Definitions of Bullying: A Comparison of Terms Used, and Age and Gender Differences, in a Fourteen-Country International Comparison. Child Development, 73, 1119-1133. https://doi.org/10.1111/1467-8624.00461

[29] Carbo, J. and Hughes, A. (2010) Workplace Bullying: Developing a Human Rights Definition from the Perspective and Experiences of Targets. Journal of Labor and Society, 13, 387-403. https://doi.org/10.1111/j.1743-4580.2010.00297.x

[30] Gradinger, P., Strohmeier, D. and Spiel, C. (2010) Definition and Measurement of Cyberbullying. Cyberpsychology: Journal of Psychosocial Research on Cyberspace, 4, Article 1. https://cyberpsychology.eu/article/view/4235/3280

[31] Greenwald, J. (2010) Broad Definition of Bullying Poses Problem for Firms. http://www.businessinsurance.com/article/20100613/ISSUE01/306139987

[32] Hollis, L.P. (2016) Bullying: Harassment by another Name, yet Still Very Much the Same. Journal of Black Sexuality and Relationships, 2, 1-10.

https://doi.org/10.1353/bsr.2016.0009

[33] McGill, N. (2016) More Research Needed to Prevent, Understand Bullying, Report Finds. The Nation's Health, 46, E30.

[34] Goldsmid, S. and Howie, P. (2014) Bullying by Definition: An Examination of Definitional Components of Bullying. Emotional and Behavioural Difficulties, 19, 210-225. https://doi.org/10.1080/13632752.2013.844414

[35] Straus, S. (2016) Is It Bullying or Sexual Harassment? Minnesota Women's Press, St. Paul, MN.

http://www.womenspress.com/main.asp?SectionID=2\&SubSectionID=692\&ArticleI $\underline{\mathrm{D}=4118}$

[36] Van Fleet, D.D. and Van Fleet, E.W. (2014) Future Challenges and Issues of Bullying in the Workplace. In: Crothers, L.M. and Lipinski, J., Eds., Bullying in the Workplace: Causes, Symptoms, and Remedies. Routledge/Taylor \& Francis, New York, 550-577.

[37] Miller, E.M. (2012) Sexual Harassment and Bullying: Similar, but Not the Same. What School Officials Need to Know. Clearing House: A Journal of Educational Strategies, Issues and Ideas, 90, 191-197. 
[38] Smolinski, J. (2011) Sexual Harassment versus Bullying. AAUW Community. http://www.aauw.org/2011/09/29/sexual-harassment-versus-bullying/

[39] Rickard, B. (N.D.) When Is Bullying Sexual Harassment? EduGuide. http://www.eduguide.org/article/when-is-bullying-sexual-harassment

[40] Van Fleet, D.D. and Van Fleet, E.W. (2012) Towards a Behavioral Description of Managerial Bullying. Employee Responsibilities and Rights Journal, 24, 197-215. https://doi.org/10.1007/s10672-012-9190-x

[41] Nurse, J.R.C., Agrafiotis, J., Goldsmith, M., Creese, S. and Lamberts, K. (2014) Two Sides of the Coin: Measuring and Communicating the Trustworthiness of Online Information. Journal of Trust Management, 1, 5. https://doi.org/10.1186/2196-064X-1-5

[42] Tepper, B.J., Moss, S.E. and Duffy, M.K. (2011) Predictors of Abusive Supervision: Supervisor Perceptions of Deep-Level Dissimilarity, Relationship Conflict, and Subordinate Performance. Academy of Management Journal, 54, 279-294. https://doi.org/10.5465/AMJ.2011.60263085

[43] Xu, G. and Li, L. (2013) Social Media Mining and Social Network Analysis: Emerging Research. Information Science Reference, Hershey, PA. https://doi.org/10.4018/978-1-4666-2806-9

[44] Abulaish, M., Islamia, J.M. and Anwar, T. (2013) A Keyphrase-Based Tag Cloud Generation Framework to Conceptualize Textual Data. International Journal of Adaptive, Resilient and Autonomic Systems, 4, 72-91. https://doi.org/10.4018/jaras.2013040104

[45] Panke, S and Gaiser, B. (2009) With My Head up in the Clouds. Using Social Tagging to Organize Knowledge. Journal of Business and Technical Communication, 23, 318-349. https://doi.org/10.1177/1050651909333275

[46] Viegas, F.B. and Wattenberg, M. (2008) Tag Clouds and the Case for Vernacular Visualization. Interactions, 15, 49-52. https://doi.org/10.1145/1374489.1374501

[47] Scott, V.C. and Wolfe, S.M. (2016) Community Psychology. Sage Publications, Inc., Thousand Oaks, CA.

[48] Guerra, F., Simonini, G. and Vincini, M. (2015) Supporting Image Search with Tag Clouds: A Preliminary Approach. Advances in Multimedia, 2015, Article ID: 439020. https://doi.org/10.1155/2015/439020

[49] Brooks, B.J., Gilbuena, D.M., Krause, S.J. and Koretsky, M.D. (2014) Using Word Clouds for Fast, Formative Assessment of Students' Short Written Responses. Chemical Engineering Education, 48, 190-198.

[50] Helic, D., Trattner, C., Strohmaier, M. and Andrews, K. (2011) Are Tag Clouds Useful for Navigation? A Network-Theoretic Analysis. International Journal of Social Computing and Cyber-Physical Systems, 1, 33-55. https://doi.org/10.1504/IJSCCPS.2011.043603

[51] Atenstaedt, R. (2012) Word Cloud Analysis of the BJGP. British Journal of General Practice, 62, 148. https://doi.org/10.3399/bjgp12X630142

[52] Cidell, J. (2010) Content Clouds as Exploratory Qualitative Data Analysis. AREA, 42, 514-523. https://doi.org/10.1111/j.1475-4762.2010.00952.x

[53] Hearst, M.A. and Rosner, D. (2008) Tag Clouds: Data Analysis Tool or Social Signaler? Proceedings of the 41 st Annual Hawaii International Conference on System Sciences (HICSS 2008), Washington DC, USA, 22 January 2008, 160. https://doi.org/10.1109/HICSS.2008.422

[54] Sinclair, J. and Cardew-Hall, M. (2008) The Folksonomy Tag Cloud: When Is It 
Useful? Journal of Information Science, 34, 15-29.

https://doi.org/10.1177/0165551506078083

[55] Kaser, O. and Lemire, D. (2007) Tag-Cloud Drawing: Algorithms for Cloud Visualization, Banff, Canada.

https://pdfs.semanticscholar.org/8dd0/06b45f14e8f5574170943fa6c85c39045f5c.pdf

[56] Lutgen-Sandvik, P. (2013) Adult Bullying. ORCM Academic Press, St. Louis, MO.

[57] Stevens, T. and Hallas, J. (2006) Bullying and Sexual Harassment: A Practical Handbook. Chandos Publishing, Oxford.

[58] Chabowski, B.R., Samiee, S. and Hult, G.T.M. (2017) Cross-National Research and International Business: An Interdisciplinary Path. International Business Review, 26, 89-101. https://doi.org/10.1016/j.ibusrev.2016.05.008

[59] Hout, M.C., Papesh, M.H. and Goldinger, S.D. (2013) Multidimensional Scaling. Wiley Interdisciplinary Reviews. Cognitive Science, 4, 93-103. https://doi.org/10.1002/wcs.1203

[60] Jaworska, N. and Chupetlovska-Anastasova, A. (2009) A Review of Multidimensional Scaling (MDS) and Its Utility in Various Psychological Domains. Tutorials in Quantitative Methods for Psychology, 5, 1-10. https://doi.org/10.20982/tqmp.05.1.p001

[61] Tzeng, J., Lu, H.H. and Li, W.-H. (2008) Multidimensional Scaling for Large Genomic Sets. BMC Biometrics, 9, 179.

[62] Pinkley, R.L., Gelfand, M.J. and Duan, L. (2005) When, Where and How: The Use of Multidimensional Scaling Methods in the Study of Negotiation and Social Conflict. International Negotiation, 10, 79-96. https://doi.org/10.1163/1571806054741056

[63] MacCallum, R. (1988) Multidimensional Scaling. In: Cattell, R.B. and Nesselroade, J.R., Eds., Handbook of Multivariate Experimental Psychology, Springer, Boston, MA, 421-445. https://doi.org/10.1007/978-1-4613-0893-5_13

[64] Shoben, E.J. (1983) Applications of Multidimensional Scaling in Cognitive Psychology. Applied Psychological Measurement, 7, 473-490. https://doi.org/10.1177/014662168300700406

[65] Robinson, S.L. and Bennett, R.J. (1995) A Typology of Deviant Workplace Behaviors: A Multidimensional Scaling Study. Academy of Management Journal, 38, 555-572. https://doi.org/10.2307/256693

[66] MacKinnon, C.A. (1979) Sexual Harassment of Working Women. Yale University Press, New Haven.

[67] Howard, J.L., Johnston, A.C., Wech, B.A. and Stout, J. (2016) Aggression and Bullying in the Workplace: It's the Position of the Perpetrator That Influences Employees' Reactions and Sanctioning Ratings. Employee Responsibilities and Rights Journal, 28, 79-100. https://doi.org/10.1007/s10672-015-9271-8

[68] Soylu, S. (2011) Creating a Family or Loyalty-Based Framework: The Effects of Paternalistic Leadership on Workplace Bullying. Journal of Business Ethics, 99, 217-231. https://doi.org/10.1007/s10551-010-0651-6

[69] Vickers, M.H. (2014) Towards Reducing the Harm: Workplace Bullying as Workplace Corruption-A Critical Review. Employee Responsibilities and Rights Journal, 26, 95-113. https://doi.org/10.1007/s10672-013-9231-0

[70] Cargile, J. (1969) The Sorites Paradox. The British Journal for the Philosophy of Science, 20, 193-202. https://doi.org/10.1093/bjps/20.3.193 